\title{
Child tracking and hidden activities observation system through mobile app
}

\author{
Mohammad Jahangir Alam', Tanjia Chowdhury ${ }^{2}$, Sohrab Hossain ${ }^{3}$, \\ Shusmoy Chowdhury ${ }^{4}$, Tanmoy Das ${ }^{5}$ \\ ${ }^{1,2,4,5}$ Department of Computer Science and IT, Southern University Bangladesh, Chittagong, Bangladesh \\ ${ }^{3}$ Department of Computer Science and Engineering, East Delta University, Chittagong, Bangladesh
}

\begin{tabular}{l} 
Article Info \\
\hline Article history: \\
Received Sep 16, 2020 \\
Revised Apr 10, 2021 \\
Accepted Apr 12, 2021 \\
\hline
\end{tabular}

\section{Keywords:}

Child monitoring

Child safety

Child tracking

Children smartphone

Hidden activities observation

\begin{abstract}
The world is changing rapidly due to information technology, and all the people around the world are busy with their jobs, and business, adjusting to this race. Now, parents are giving more time at their business, office, and jobs, instead of passing the time at home, but they always get worried and scared about their children due to abuse of Information Technology and the country's law and order situation. So, parents are wanted to track and monitor their child's activities and location from anywhere to resolve their pressure. But is not possible for every parent to monitor their child physically due to many reasons. This paper presents a system that will help parents monitor their child activities from anywhere using a mobile phone to solve the problem. This android app uses global positioning system (GPS) and mobile services to find the child location and secretly stored all the call logs, hort message service (SMS) logs, contact lists, and accurate locations without knowing the children. Children assume that they are using Facebook, browsing the net or watching videos from youtube. It will not hamper any activities of the child. Parents can check all the activities of children using this app.
\end{abstract}

This is an open access article under the CC BY-SA license.

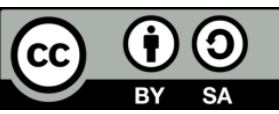

\author{
Corresponding Author: \\ Sohrab Hossain \\ Department of Computer Science and Engineering \\ School of Science, Engineering, and Technology \\ East Delta University \\ Chittagong, Bangladesh \\ Email: sohrab.h@eastdelta.edu.bd
}

\section{INTRODUCTION}

Due to the rapid development of cities and growing industries in almost all the countries worldwide, more people live in the city rather than in the village. Parents keep their children with them due to many urban areas like better school, health care facilities, baby care centres, and parents. As per the United Nations (U.N.) World Urbanization report, more people living in urban areas than rural areas. According to the report, in 2017, 4.1 billion people lived in urban areas, which indicates that more than $55 \%$ of people are residing in cities [1]. The statistic report published by S. O'Dea, February 28,2020 , shows the predicated quantity of mobile users worldwide from 2019 to 2023.

By 2020, mobile users worldwide are predicted to rise to 6.95 billion, increasing to 7.33 billion in 2023 [2]. Another report on smartphone users showed that the number of users in 2019 was 3.2 billion worldwide and is forecast to grow by several hundred million in the next few years, which would be 3.8 billion in 2021. The top smartphone users belong to China, India, and the United States, easily exceeding the 100 million user mark [3]. Many children are also using the smartphone in the world; they use the mobile to 
access the internet and play games. The United States of America USA's report says that more than half of children use a mobile phone, which is approximately $53 \%$ by 11 and $84 \%$ now have their smartphones [4]. Another survey report on U.K. children who belong to the age of 5-16 has shown that 53 per cent of youngsters owned mobile phones by around the age of seven. It also said that $90 \%$ of children have their device by the age of 11, and owning a smartphone is "almost universal" once children are in secondary school [5]. Another report based on four countries like Japan, India, Egypt, and Paraguay has been shown that Egypt has 94\%, followed by Paraguay with $78 \%$, India 57\%, and Japan $52 \%$. The report has compared mobile phone usage rates by underage users of various age groups among the four countries. Egypt has a high rate of early age mobile users: more than $80 \%$ of Egyptian children use mobile from age 8. In India, Japan, and Paraguay, children mobile usage rates increasing from age 10 [6]. So, it is very clear evidence that children are very interested in using smartphones worldwide, which is currently a very concern issue.

On the other hand, As per Dr A.P.J Abdul Kalam's words, "Youngsters are the future pillars of one's nation", today's children are tomorrows leaders; preserving their dreams and lives a better future is crucial for every nation [7]. Nowadays, kids' can know about present technology through a smart device. It may affect their physical and mental development and hamper their educational and communal life. Parents are getting worried about these things [8]-[10]. Considering the present situation, parents need smart technology for monitoring and controlling their children's movement. In our digital era, children use smart devices like tablets.

For this reason, parents need to know how many times they use tablets, which type of website they visit, and which site they spend their time on more. Everything is possible through using automated technology. So parents need automated technology for this purpose [11]. In this circumstance, every parent tries to give their best concern to take care of their children to save them from the dark world and the technology's bad effects to save their children's future. The research has been given more focus on parental control over children's mobile devices.

\section{LITERATURE REVIEW}

A smart mobile phone provides various up to date services to us. Using the global positioning system (GPS), we can get to know our devices' geographic location and give information through hort message service (SMS) service. Al-Mazloum et al. used these two services in their proposed system. They introduced GPS and SMS-based child tracking system using smart phone [12]. This paper describes how a smart mobile phone helps parents track their children in real-time. Most kids and parents use an android mobile phone, and they know the mobile phone's available service. Their proposed system consists of two sides, the child side and the parent side. A request SMS goes to the child's device to know the child's exact location from the parent device. After getting the request SMS, the child's device replies to the parent's device's GPS position.

Kothawade et al. [13] proposed a system "multi-platform application for parent and school using GPS tracking”. In this paper, they developed a GPS based application system for an organization and parents mobiles. The organization can use this application for monitoring and tracking the location of the school buses. Parents can get the addresses of their children and locate them on his/her mobile devices. School authority also can monitor and track the school buses timely and ensures the safety of children. It also allows parents to track real-time information about the school bus during travels. Almomani et al. [14] proposed a system with two types of applications a web application and a mobile application for a user facility. A user can access this system at any time from anywhere.

There are two sides: client-server. The server-side carries a GPRS, a web, and an SMS server, and the client-side contains a GPS tracker and a GPS modem. The user information is stored in the database on the server-side [14]. There is another similar concept used by Al-Suwaidi and Zemerly [15] in their proposed system named "locating friends and family using mobile phones with a global positioning system (GPS)". They have also developed two approaches: the client-server approach. This paper showed both clients have the same control and command privileges, whereas the other system does not provide it.

Gao et al. [16] developed a security method named child guard on smart devices for observing children's activities in real-time. Guardians used this system at a low cost, and they can get better benefits by using this system. Satish et al. [17] described their paper about an android application used to track missing children. The android application works with two services: GPS and SMS service. The GPS is used to track the location of the missing child. If GPS service is unable, the application can work with SMS service by sending and receiving the message. There is another paper where the researcher Bhoi et al. [18] implements a project based on a particular area for each child. When the child comes out of this specific area of their school, then an alert message sends to the parent's mobile phone by using a panic switch. Saranya et al. [19] proposed a child monitoring system based on android phones for the children's security. This system helps the parents to know whether their children are safe or not. This system consists of two functions. The software hand function monitors the child's activities, and the danger zone function alerts the guardians about their children's location 
by using GPS sensors, acceleration sensors, and mobile geographic information systems GIS. Subramanian and Govindarajan, [20] discussed different type of Location Prediction Techniques in their study. In this paper, they have used data mining techniques to find mobile users' movements' locations. Kaittan et al. [21] designed a monitoring system for infant baby in "Smart management system for monitoring and control of infant baby bed". This paper designed a baby bed with an intelligent system and used the sensor to monitor the baby. Okilas et al. [22] designed a "Location-based service for information publication using GPS on android-based mobile phone". In this paper, the difference in the accuracy of the GPS readings used in mobile the shifting point is about 18 meters. Table 1 shows recent child tracking researches, methods, and limitation of current researches. In the discussion, most researchers focused on children monitoring systems to protect them from any unwanted accident, missing, and making them secure and safe. But in our research, we introduced a system that will be used to save the children and be used to observe their mobile activities without children's consent.

Table 1. Taxonomy of related works

\begin{tabular}{|c|c|c|c|}
\hline Article & Specification & Method & Limitation \\
\hline [23] & $\begin{array}{l}\text { Focusing on conflict of language } \\
\text { selections between parents and their } \\
\text { children, the study focuses on families } \\
\text { who migrated from rural to urban areas }\end{array}$ & $\begin{array}{l}\text { Putonghua is a language } \\
\text { management strategy }\end{array}$ & $\begin{array}{l}\text { This paper focuses only on the conflict of } \\
\text { language between rural parents and their urban } \\
\text { children. However, it does not focus on the } \\
\text { tracking of child activities. }\end{array}$ \\
\hline [24] & $\begin{array}{l}\text { Focusing on child's play activity level, } \\
\text { activity type, and public interaction } \\
\text { during play }\end{array}$ & t-tests & $\begin{array}{l}\text { This paper finds a pattern between play and } \\
\text { social interaction. However, it does not deal with } \\
\text { the hidden behaviour of children }\end{array}$ \\
\hline [26] & $\begin{array}{l}\text { Focusing on harmful technological effect } \\
\text { on human behaviour and how technology } \\
\text { hamper the harmony of man and nature }\end{array}$ & $\begin{array}{l}\text { an integrated system of } \\
\text { environmental education } \\
\text { of preschool children }\end{array}$ & $\begin{array}{l}\text { This paper only focuses on the bad effect of } \\
\text { technology on a human being. However, it does } \\
\text { not explain how technologies hamper children } \\
\text { creativities. }\end{array}$ \\
\hline [28] & $\begin{array}{l}\text { Focusing on childhood obesity } \\
\text { prevention interventions. }\end{array}$ & $\begin{array}{l}\text { quasi-experimental } \\
\text { pragmatic trial }\end{array}$ & $\begin{array}{l}\text { Only focus on the childhood obesity epidemic. } \\
\text { However, it does not explain the technological } \\
\text { impact on obesity. }\end{array}$ \\
\hline [29] & $\begin{array}{l}\text { Focusing on autism associated with } \\
\text { unusual activation during face processing }\end{array}$ & $\begin{array}{l}\text { representational } \\
\text { similarity analysis }\end{array}$ & $\begin{array}{l}\text { Only focus on autistic children behaviour. But } \\
\text { Autistic children psychological activities can be } \\
\text { observed using mobile apps. }\end{array}$ \\
\hline
\end{tabular}

\section{RESEARCH METHOD}

In our proposed system, we emphasized the security of a child. This system consists of two sides: child and parent side. The main aim of this system helps parents to observe their children's activities from anywhere. In Bangladesh, most of the parents are working outside of the house. They cannot look after their children by keeping their side. They give a smartphone to their children to know the activities of them. That's why we have developed an android app for a mobile device that provides various services to parents. In the children's mobile phone, there is a secret app. From this app, parents can see where their children are going, what they are using on their mobile phone, and which website they have visited. Parents can also listen to their call history from call records. Figure 1 shows the block diagram and Figure 2 flow chart of the developed system.

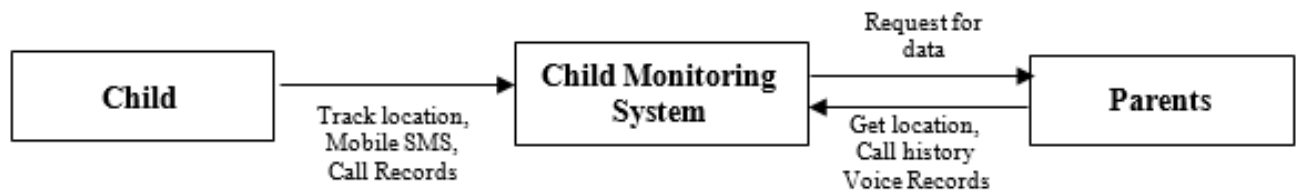

Figure 1. Block diagram

Figure 2 shows the application process flow using flow symbols, where a user has to login into the system. If the user logins as a child, the user can access the application, browse different websites, watch videos 
through youtube, and call any person, but all the information will be stored in the database hidden from children. On the other hand, after login into the system, a parent can check the child's smartphone and view all activities.

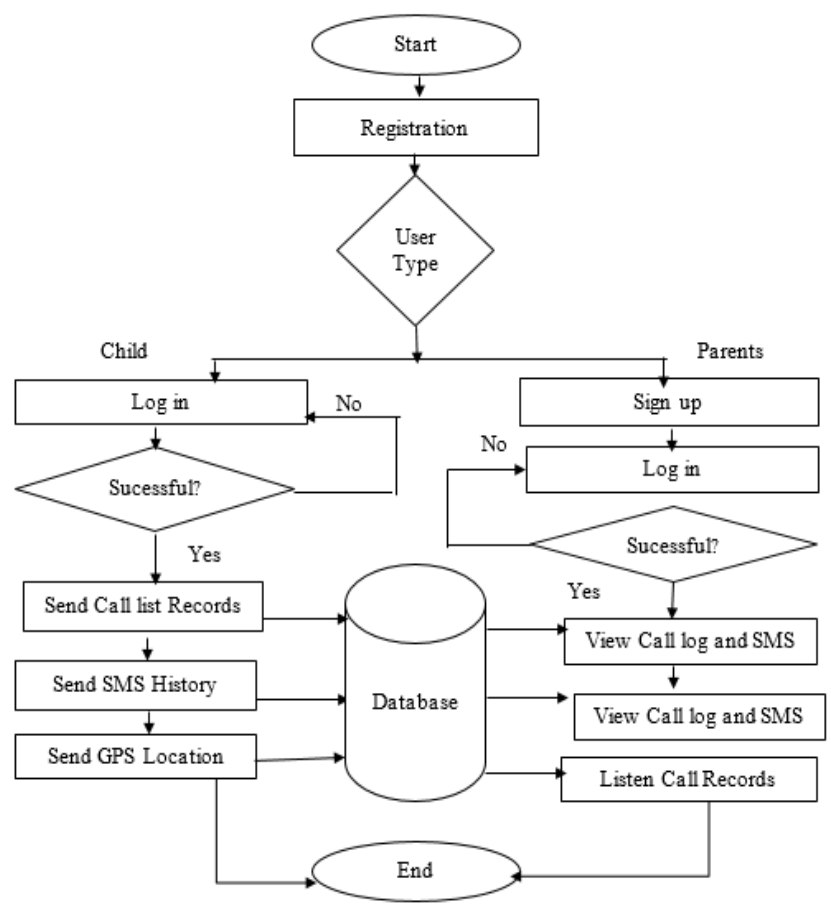

Figure 2. Flowchart for child monitoring application

\section{IMPLEMENTATION}

As we know, there are two account options in this child monitoring system: one for parent and another one for a child, as Figure 3. At first, running this app needs registration, then log in. To sign up for the system, a child must have to use email and password, but the parents must complete this signup task without informing them on the children's smartphone. Figure 3 is also showing the login page of the child page. Besides this, parents have to install the same app on their smartphone and register by giving their Name, email address as given in the child app, and the password as like in Figure 4. After that, a parent can log in to the system to view the details of the children.
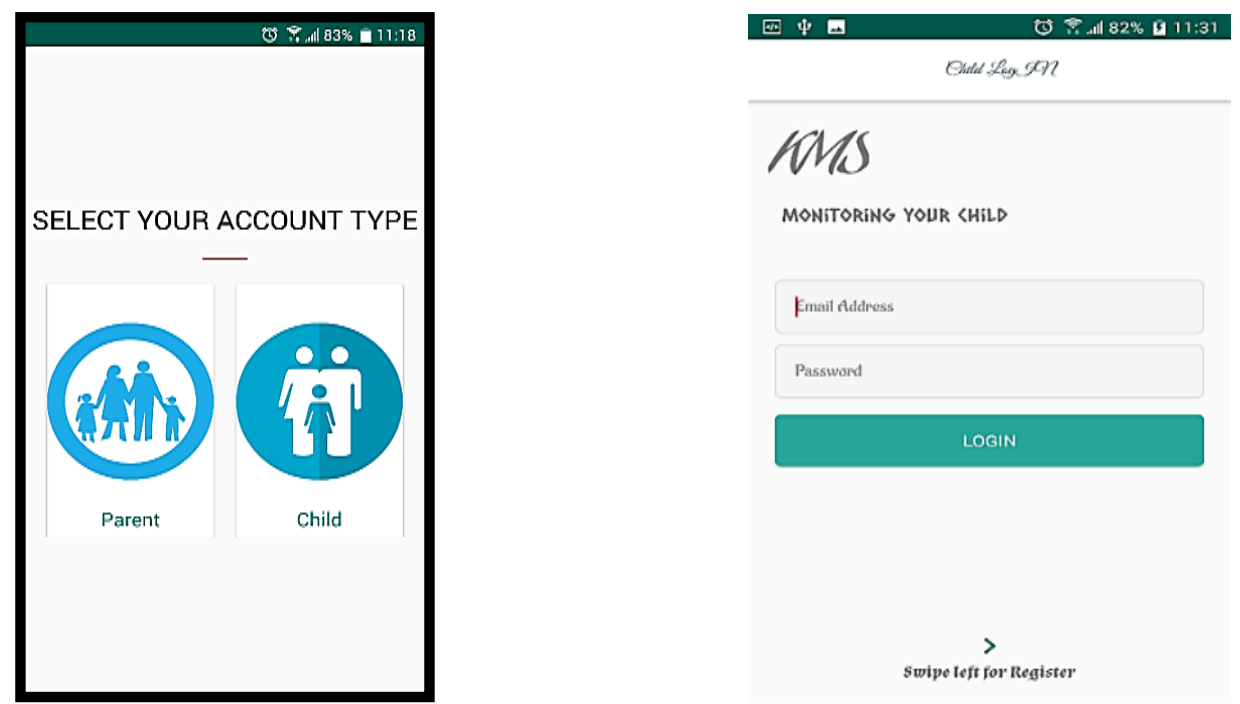

Figure 3. The home screen of child monitoring system (CMS) and login page of child 


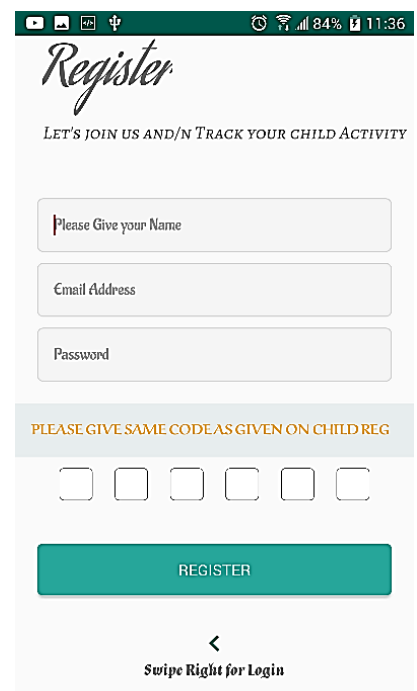

Figure 4. Signup page for parents

\section{RESULTS AND DISCUSSION}

This section describes the outcomes of our proposed method. Sub section 5.1 focus parents' login procedure and child call/browsing history. In the next sub section, child registration procedure and their activities are explained. Child does not aware of the parents' section and their monitoring procesure.

\subsection{Parents section}

Primarily, we described the parent's section. To login into the system, parents have to input all of the required information like a name, password, as Figure 5. If all the information match with the database, then a guardian can be able to login into the system, that a parent can track the current child location, as Figure 6, which shows the page of the GPS location of the child application, this is a real-time location track from the child mobile.

Furthermore, a parent can check the call history from their children's mobile phone as Figure 7 to be aware of their childhood friends list and gossiping them. Besides this, parents are also able to view the SMS history of their children and also can check the internet browsing history from their children's mobile phone as Figure 8 which is very important for a parent to monitor their children's all smartphone activities and protected them from any misuse of smartphone.

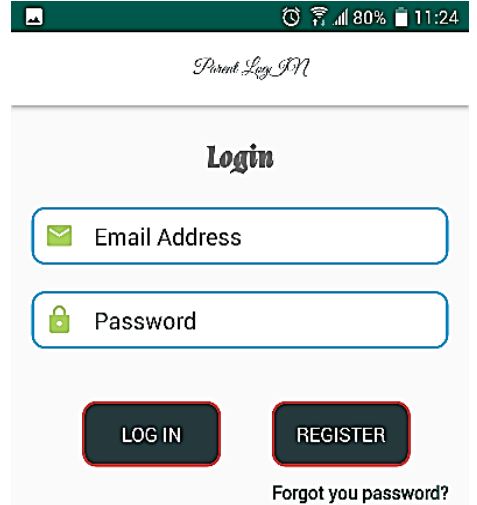

Figure 5. A sign-in page for parents

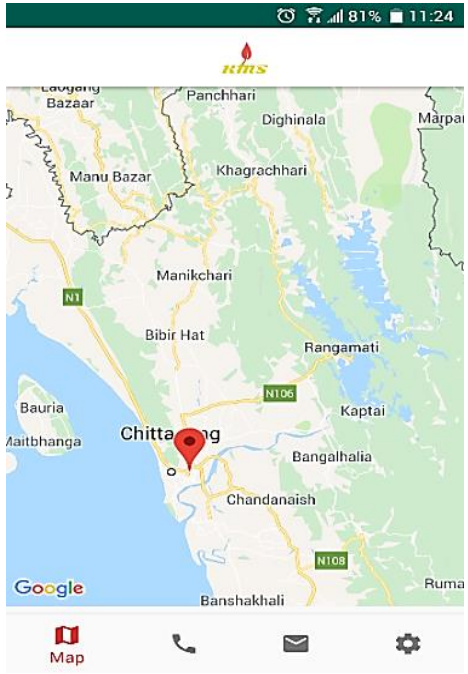

Figure 6. GPS location 


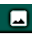
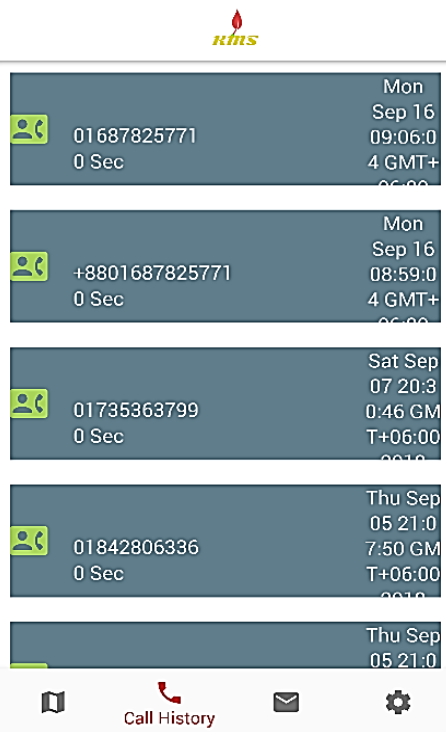

Figure 7. Call history of child mobile

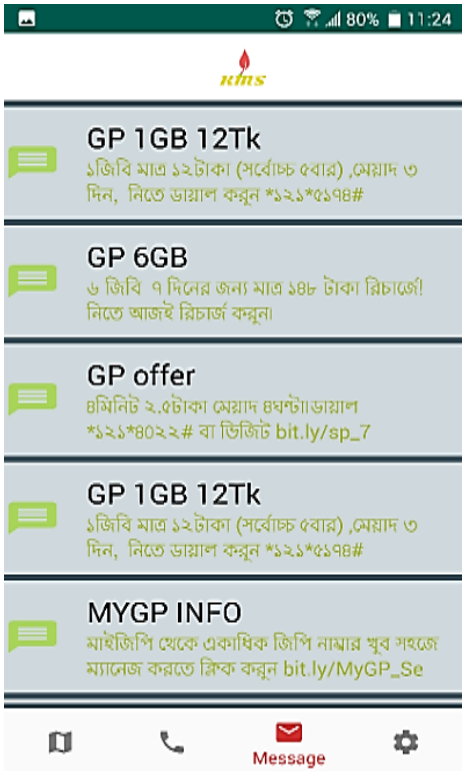

Figure 8. SMS History

\subsection{Child section}

Secondly, the activities of the children in this app are going to be discussed in this section. At first, this app has to be installed on child smartphone by the parents, and a child cannot know about this app. Parents must have to manage this app confidentially. They will register, $\log$ in to the child mobile phone app secretly. Figure 9 shows the child's registration page; according to Figure 10, in the child section, use the key "789789" used in the parent's application. In child smartphone, this app looks like a Facebook page, and they can use this page to login into Facebook. The child can enjoy all facilities of Facebook as usual. But, behind the Facebook page, the app will work hidden as Figure 10.

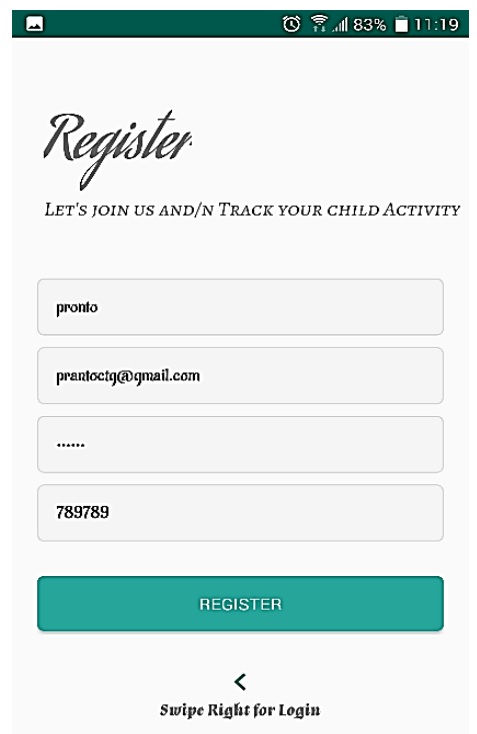

Figure 9. Child registration page

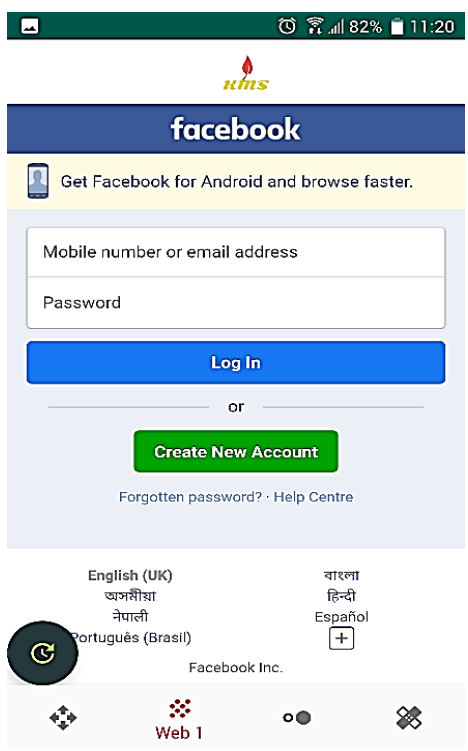

Figure 10. Browser page of the child app

Generally, children like to watch movies on YouTube. In Figure 11 shows a sample scenario of YouTube, which a child likes to use. But, when parents will log in to the system from parent's apps, they can get all information about watched movies or videos of children, which is crucial for parents to monitor their child activities and save them from the virtual world's dark side. Similarly, children can visit different websites 
from their smartphones without any obstacles and can search any websites using a search engine like Google, shown in Figure 12. Parents can check the browsing history from their smartphones and be tenseless about their children's online activities and can take any steps if necessary to protect them from misuse of the virtual world and appreciate their good activities without notifying them.

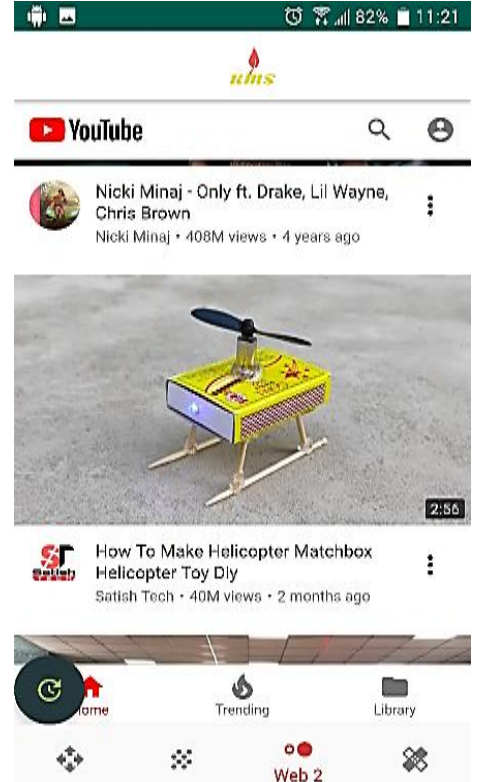

Figure 11. Browser page of the child app

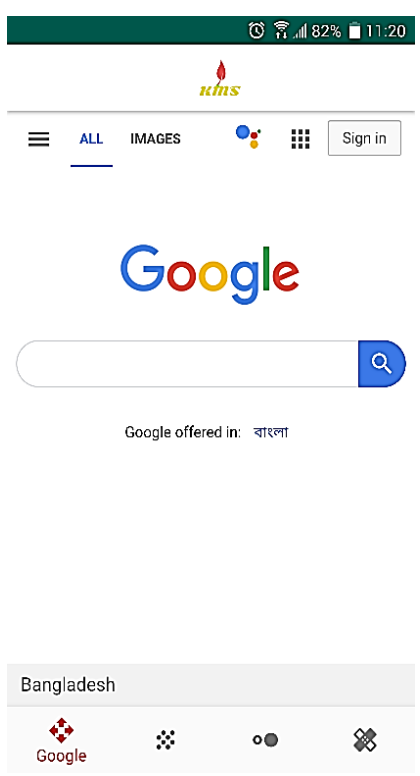

Figure 12. Browser page of the child app

\section{CONCLUSION}

It is a big benefit for the parents that many children are using smartphone while in school, and that is why the guardian can monitor the children's activities and track the children through accessing smartphone, which is very important for busy guardians. This paper presented research that will help guardians monitor their child activities from anywhere using smartphone whenever they want from any location. They can also check their children current location, which websites they have visited, how many calls. They have given to friends or others the SMS logs and which video they have watched without informing and hampering the children's activities to be aware of their child activities in the future if they find any terrible habit of their children. This app is very useful for parents to monitor their children and to resolve their mental pressure.

\section{REFERENCES}

[1] World Urbanization Prospects, Department of Economic and Social AffairsPopulation Dynamics, United Nations, 2017. [Online]. Available: https://population.un.Org/wup/

[2] Forecast number of mobile users worldwide from 2019 to 2023, Statista, 2020. [Online]. Available: https://www.statista.com/statistics/218984/number-of-global-mobile-users-since-2010/

[3] How Many People Have Smartphones in 2020?, Oberlo. [Online]. Available: https://www.oberlo.com/statistics/howmany-people-have-smartphones

[4] A. Kamenetz, It's A Smartphone Life: More Than Half Of U.S. Children Now Have One, npr, 2019. [Online]. Availbale: https://www.npr.org/2019/10/31/774838891/its-a-smartphone-life-more-than-half-of-u-s-children-nowhave-one

[5] Most Children Own Mobile Phone by Age of Seven, Study Finds, The Guardian, 2020. [Online]. Available: https://www.theguardian.com/society/2020/jan/30/most-children-own-mobile-phone-by-age-of-seven-study-finds

[6] DOCOMO, GSMA NTT, "Children's use of mobile phones-An international comparison 2011," GSM Association and Mobile Society Research Institute, 2018.

[7] N. Senthamilarasi, N. D. Bharathi, D. Ezhilarasi, and R. B. Sangavi, "Child Safety Monitoring System Based on IoT," Journal of Physics: Conference Series, vol. 1362, no. 1, ,2019, doi: 10.1088/1742-6596/1362/1/012012.

[8] Campbell, Marilyn, "The impact of the mobile phone on young people's social life," Social Change in the 21 Century 2005 Conference Proceedings, 2005, pp. 1-14. 
[9] Sara Thomée, Annika Härenstam, and Mats Hagberg, "Mobile phone use and stress, sleep disturbances, and symptoms of depression among young adults-a prospective cohort study," BMC public health, vol. 11, no. 1, pp. 1-11, 2011.

[10] M. Hossain, "Impact of mobile phone usage on academic performance," World Scientific News, vol. 118, pp. 164-180, 2019.

[11] A. M. Elmogy and K. Elkhowiter, "Parental Control System for Mobile Devices," International Journal of Computer Applications, vol. 177, no.3, pp. 16-23, Nov. 2017, doi: 10.5120/ijca2017915687.

[12] A. Al-Mazloum, E. Omer, and M. F. A. Abdullah. "GPS and SMS-Based Child Tracking System Using Smart Phone," International Journal of Electronics and Communication Engineering, vol. 7, no. 2, pp. 238-241, 2014, doi: 10.5281/zenodo.1335994.

[13] P. Kothawade, S. Tompe, M. Walavalkar, and R. Mirgunde, "Multi-Platform Application for Parent and School using GPS tracking," International Journal of Advanced Research in Computer and Communication Engineering, vol. 5, no. 4, pp. 80-83, April 2016, doi: 10.17148/IJARCCE.2016.5422.

[14] I. M. Almomani, N. Y. Alkhalil, E. M. Ahmad, and R. M. Jodeh, "Ubiquitous GPS Vehicle Tracking and Management System," 2011 IEEE Jordan Conference on Applied Electrical Engineering and Computing Technologies (AEECT), 2011, pp. 1-6, doi: 10.1109/AEECT.2011.6132526.

[15] G. B. Al-Suwaidi and M. J. Zemerly, "Locating Friends and Family Using Mobile Phones with Global Positioning System (GPS)," 2009 IEEE/ACS International Conference on Computer Systems and Applications, 2009, pp. 555-558, doi: 10.1109/AICCSA.2009.5069380.

[16] Z. Gao, H. Guo, Y. Xie, Y. Luo, H. Lu, and K. Yan, "ChildGuard: A Child-Safety Monitoring System," in IEEE MultiMedia, vol. 24, no. 4, pp. 48-57, October-December 2017, doi: 10.1109/MMUL.2017.4031309.

[17] M. Satish, C. Nandlal, and G. Sandip, "Child Tracking System using Android phones," International Journal of Advanced Research in Computer Engineering \& Technology, vol. 4, no. 4, April 2015.

[18] R. N. Bhoi, V. V Shete, and S. B. Somani, "Android Based Child Tracking System," International Journal of Innovative Research in Computerand Communication Engineering, vol. 3, no. 7, pp. 6536- 6542, July 2015, doi: 10.15680/ijircce.2015. 0307028.

[19] A. Saranya, C. Venkatesh, and S. Selva Kumar, "Design and Implementation of Automatic Child Monitoring (ACM) System Using Wireless Network," International Journal of Computer Science and Mobile Computing, vol. 5, no. 4, pp. 356-363, 2016.

[20] J. V. Subramanian and S. Govindarajan, "A Study of Mobile User Movements Prediction Methods," International Journal of Electrical and Computer Engineering, vol.8, no.5, pp. 3112-3117, Oct. 2018, doi: 10.11591/ijece.v8i5.pp3112-3117.

[21] A. S. Kaittan, S. M. Hameed, N. K. Ali, and M. H. Ali, "Smart Management System for Monitoring and Control of Infant Baby Bed," International Journal of Electrical and Computer Engineering, vol.10, no.5, pp. 5025-5031, Oct. 2020, doi: 10.11591/ijece.v10i5.pp5025-5031.

[22] A. F. Okilas, S. D. Siswanti, and M. D. Rachman, "Location Based Service for Information Publication Using GPS on Android-Based Mobile Phone," Proceeding of International Conference on Electrical Engineering, Computer Science and Informatics (EECSI 2014), 2014, pp. 190-197.

[23] H. Yang and X. L. Curdt-Christiansen, "Conflicting Linguistic Identities: Language Choices of Parents and Their Children in Rural Migrant Workers' Families," Current Issues in Language Planning, pp. 1-19, 2020, doi: 10.1080/14664208.2020.1748370.

[24] Z. Wahl-Alexander and C. A. Morehead, "An Observational Assessment of Physical Activity Levels and Social Behavior During Residential Summer Camp Unstructured Time," American Journal of Health Promotion, vol. 34, no. 4, pp. 387-392, 2020, doi: 10.1177/0890117119897191.

[25] I. van de Kolk, et al., "Study Protocol for the Evaluation of "SuperFIT", a Multicomponent Nutrition and Physical Activity Intervention Approach for Preschools and Families," International Journal of Environmental Research and Public Health 17.2 (2020): 603, doi: 10.3390/ijerph17020603.

[26] Demidov A. A., T. A. Syrina, and A. L. Tretyakov, "Development of Digital Skills and Media Education System: From the Organization of Environmental Education of Preschool Children to the ICT Competence of Teachers," Медиаобразование, vol. 60, no. 1, pp. 11-23, 2020, doi: 10.13187/me.2020.1.11.

[27] B. Johnson, C. Jobst, R. Al-Loos, W. He, and D. Cheyne, "Individual Differences in Motor Development During Early Childhood: An MEG Study," Developmental Science, vol. 23, no. 5, 2020, doi: 10.1111/desc. 12935.

[28] M. W. Long, et al., "Evaluation of a Pragmatic Trial of a Collaborative School-Based Obesity Prevention Intervention in a Low-Income Urban District," Preventive Medicine, vol. 133, 2020, doi: 10.1016/j.ypmed.2020.106020.

[29] K. O'Hearn, B. Larsen, J. Fedor, B. Luna, and A. Lynn, "Representational Similarity Analysis Reveals Atypical Age-Related Changes in Brain Regions Supporting Face and Car Recognition in Autism," NeuroImage, vol. 209, 2020, doi: 10.1016/j.neuroimage.2019.116322. 